\title{
Effects of soil properties and biosurfactant on the behavior of PAHs in soil-water systems
}

\author{
Hui $\mathrm{Yu}^{1,2^{*}}$, Huining Xiao ${ }^{1}$ and Dunling Wang ${ }^{3}$
}

\begin{abstract}
Background: The interactions among biosurfactant, soil components and PAHs govern the efficiency of biosurfactant enhanced remediation, which was still poorly studied. In this study, we investigated effects of biosurfactant and soil properties on sorption and desorption of phenanthrene (PHE) and pyrene (PYR) in soil water systems. Two kinds of soil samples (ditch and under plant) from the same petroleum contaminated site in western Canada were applied.

Results: The results indicate that soil organic matter (SOM) was the predominant factor that affects PAHs sorption onto soil. The SOM content in ditch soil was half of that in under plant soil, therefore ditch soil showed less sorption affinity to PAHs than under plant soil. We also examined the combined effects of soil DOM and biosurfactant on desorption of PAHs. The results indicated that more PAHs were desorbed from ditch soil than the under plant soil under the combined conditions. The SOM was still the key factor that determined desorption of PAHs. Besides, competitions among PAHs, DOM and surfactant for sorption sites exist. In high solute concentration system, the competition for sorption site was more severely than low concentration system and more PAHs were sequenced in soil phase in high PAH concentration system. Also in low biosurfactant system, less PAHs were desorbed from soil.
\end{abstract}

Conclusions: The study results should be helpful in broadening knowledge of biosurfactant enhanced bioremediation of PAHs.

Keywords: PAHs; Biosurfactant; Soil organic matter; Desorption

\section{Background}

Polycyclic aromatic hydrocarbons (PAHs) have drawn environmental and health concern due to their known or suspected cancerogenicity and mutagenicity (Wilcke 2000; Shin et al. 2006). PAHs emitted mainly from anthropogenic activities and accumulate in environment owing to their highly hydrophobic properties. In soil/ ground water system, PAHs are largely sorbed into soil organic materials, which significantly restrict their transformation and bioavailability. The sorption behavior of PAHs in soil is greatly influenced by a number of soil characteristics, including soil organic matter (SOM), $\mathrm{pH}$, clay minerals and soil texture (Cao et al. 2008). SOM

\footnotetext{
* Correspondence: bestyuhui@gmail.com

'Department of Chemical Engineering, University of New Brunswick, Fredericton, NB, E3B 5A3, Canada

${ }^{2}$ MOE Key Laboratory of Regional Energy Systems Optimization, S\&C Academy of Energy and Environmental Research, North China Electric Power University, Beijing 102206, China

Full list of author information is available at the end of the article
}

is considered as the most important component affecting the behavior of hydrophobic organic contaminants (HOCs) in soil and sediment (Wen et al. 2007). The dissolved fraction of SOM, dissolved organic matter (DOM), which has the capability of mobilizing PAHs in soil water system, would also influence the mobility and bioavailability of HOCs in environment (Akkanen et al. 2005; Pan et al. 2007; Raber et al. 1998).

The use of biosurfactant to enhance the remediation is a promising approach to remove PAHs from soil system (Zhu and Aitken 2010). Surfactants are amphiphilic compounds and are known to improve the efficiency of desorption of HOCs through enhancing the solubility of HOCs in aqueous systems, thus facilitating their mobility and bioavailability (Yu et al. 2007; Abu-Zreig et al. 2003; Cheng and Wong 2006). Surfactant could greatly enhance the solubility of HOCs at concentrations higher than its critical micellar concentration (CMC). Biosurfactant is naturally produced surfactant. Compared with traditional

\section{它}


surfactant, biosurfactant has relatively higher biodegradability, biocompatibility, and environmental resilience (Kuyukina et al. 2005; Cheng et al. 2004; Makkar and Rockne 2003). However, the efficiency of biosurfactant enhanced bioremediation can be also affected by the soil properties due to its potential to be adsorbed by soils, which would enhance contaminant retention in soil, thus their bioavailability (Rodriguez-Escales et al. 2013; Lee et al. 2005; Lu and Zhu 2012).

Therefore, the fundamental interactions among biosurfactant, soil components and PAHs jointly govern the efficiency of biosurfactant enhanced remediation and should be detailed investigated. Recently there has been increasing study on the combined effects of surfactant and SOM on HOCs partition (Cheng and Wong 2006; Wan et al. 2011; Rodriguez-Escales et al. 2013). However, these studies put more efforts on additive organic matter, such as DOM or artificial soil particles. Also, the combination of soil properties and surfactant on the partitioning of PAHs has been poorly investigated.

Given the concerns mentioned above, the objective of this study is to explore the interactive mechanisms of soil properties and biosurfactant on desorption of two PAHs: phenanthrene (PHE) and pyrene (PYR) in soilwater systems. We mainly focus on the soil DOM which has been proven to be the most important factors affecting the behavior of PAHs. Two types of soil samples collected from the same western Canadian site were compared.

\section{Results and discussion}

\section{Soil and DOM characterization}

It is known that soil properties such as organic matter, $\mathrm{pH}$, cation exchange capacity (CEC), clay minerals and soil texture will affect the sorption-desorption of PAHs (Hwang 2001; Kuyukina et al. 2005; Cao et al. 2008; Chen et al. 2009a). Among them, soil SOM and clay minerals are considered as the two most chemically active components of soils (Hwang and Cutright 2003; Lu and Zhu 2012).

The characteristics of two kinds of site soils are presented in Table 1. According to the result of soil classification, the under plant soil belonged to sand loam which has a high sand mineral content (60\%) and a normal clay content (28\%). The ditch soil is classified as clay loam, which has relatively higher clay mineral content (37\%). Of the clay minerals, the contents of smectite, illite and kaolinite in ditch soil were $7.8 \%, 9.4 \%$ and $2.9 \%$, respectively, which were slightly higher than those in under plant soil.

Smectite, illites and kaolinite are the three common clay minerals which have the greatest impact on sorption/desorption because of their high surface area and CEC as well as their surface reactivities (Sheng et al.
Table 1 Properties of studied soil samples

\begin{tabular}{llll}
\hline Property & & Under plant & Ditch \\
\hline pH(CaCl & ) & 6.96 & 7.02 \\
Organic matter & 8.65 & 4.3 \\
C:N ratio & 12.55 & 8.98 \\
Cation exchange capacity (cmol/kg) & 29.34 & 38.79 \\
Coarse sand >0.25 mm (\%) & 14.5 & 2.4 \\
Fine sand 0.25-0.02 (\%) & & 42.5 & 35.6 \\
Silt 0.02-0.002 mm (\%) & & 15 & 25 \\
Clay < 0.002 mm (\%) & & 28 & 37 \\
Classification ${ }^{\text {a }}$ & & Sand loam & Clay loam \\
Clay mineralogy (\% wt) & Smectite & 6.2 & 7.8 \\
& Illites & 9.3 & 9.6 \\
& Kaolinite & 2.4 & 2.9 \\
& Quartz & 54.8 & 42.7 \\
& Potash feldspar & 13.5 & 23.6 \\
& Plagioclase & 10.4 & 9.7 \\
& Amphibole & 1.7 & 1.7 \\
& Calcite & 1.7 & 1.2 \\
\hline
\end{tabular}

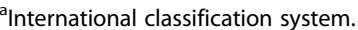

2001; Hwang et al. 2003). Smectite is the most expandable clay on wetting with a 2:1 ratio of $\mathrm{Si}$ : $\mathrm{Al}$ and can provide an internal surface area as high as $570-660 \mathrm{~m}^{2} / \mathrm{g}$ (Brady and Weil 2000). Illite is nonexpandable 2:1 type minerals dioctahedral, aluminous, and contains nonexchangeable $\mathrm{K}$ as the major interlayer. Kaolinite is a 1:1 layered silicate with alternating silicon oxide tetrahedral sheets and aluminum hydroxide octahedral sheets, which could provide large external surface area for HOCs binding (Hwang and Cutright 2003; Woods 2004). SOM is often considered as the dominant sorption phase for organic contaminants in soil-water systems (Sheng et al. 2001). The SOM content in ditch soil is only half of that in under plant soil. For other soil characteristics given in Table 1, the $\mathrm{pH}$ in ditch soil was slightly higher than that in under plant soil and the CEC of ditch soil $(38.79 \mathrm{cmol} / \mathrm{kg})$ was also a little higher than under plant soil $(29.34 \mathrm{cmol} / \mathrm{kg})$.

For the DOM characterization, the concentration of DOM extracted from the under plant soil and ditch soil showed great difference, with the values of 610.2 and $207.8 \mathrm{mg} / \mathrm{kg}$, respectively. The DOM content in under plant sample was much higher than that in ditch soil sample, which was in proportion to their total organic matter content. The E4/E6 ratio of under plant soil and ditch soil were 8.3 and 8 , respectively, which means the DOM derived from ditch soil had relatively higher molecular weight. When the DOM content in all samples was adjusted to $20 \mathrm{ppm}$, the specific UV absorptions at $254 \mathrm{~nm}$ were 0.761 and $0.792 \mathrm{~L} \mathrm{mg}^{-1} \mathrm{~m}^{-1}$ for DOM 
derived from under plant soil and ditch soil, respectively. The aromatic carbon content in ditch DOM sample was also higher than that in under plant DOM sample.

The structural difference of two soil DOMs was analyzed through ${ }^{1} \mathrm{H}$ NMR. The two DOM samples exhibited similar peak shapes from the ${ }^{1} \mathrm{H}$ NMR spectra (Figure 1), both showed simple and well-defined peaks, which indicated that similar compositions in the functional groups of DOM. The identified peaks in the ${ }^{1} \mathrm{H}$ NMR spectra were assigned to aliphatic $\mathrm{H}$ in methyl protons and main-chain methylene (0.8-1.5 ppm), carbonyl group in an acid or ester at $\beta-C(1.8 \mathrm{ppm})$, protons to ethers or hydroxyl group (3.6 ppm), esters (4.0 ppm), water $(4.8 \mathrm{ppm})$ and carboxyl group $(8.4 \mathrm{ppm})$. Both samples showed these identified peaks with different responses. The DOM from ditch soil showed lower ratio of aliphatic $\mathrm{H}$ in methyl protons to main-chain methylene. Ditch soil DOM also showed fewer amounts of olefinic compounds as well as oxygen and nitrogen. Besides, for the spectrum of ditch DOM, there were multiple peaks between 1.8 to $3.6 \mathrm{ppm}$. This indicated the component of high molecules of polymers; $\mathrm{H}$ may be bonded to aromatic $\mathrm{C}$ in methine group or bounded to $\mathrm{O}$ or $\mathrm{N}$ in aliphatic $\mathrm{C}$. However, the detailed composition of the polymers needed to be further analyzed (Figure 2).

For under plant DOM, FTIR analysis was conducted to further clarify its chemical functions and following characteristic bands can be found. A broad band at 3300 and $3500 \mathrm{~cm}^{-1}$ was assigned to $\mathrm{H}$-bonds, $\mathrm{OH}$ groups.

(a)
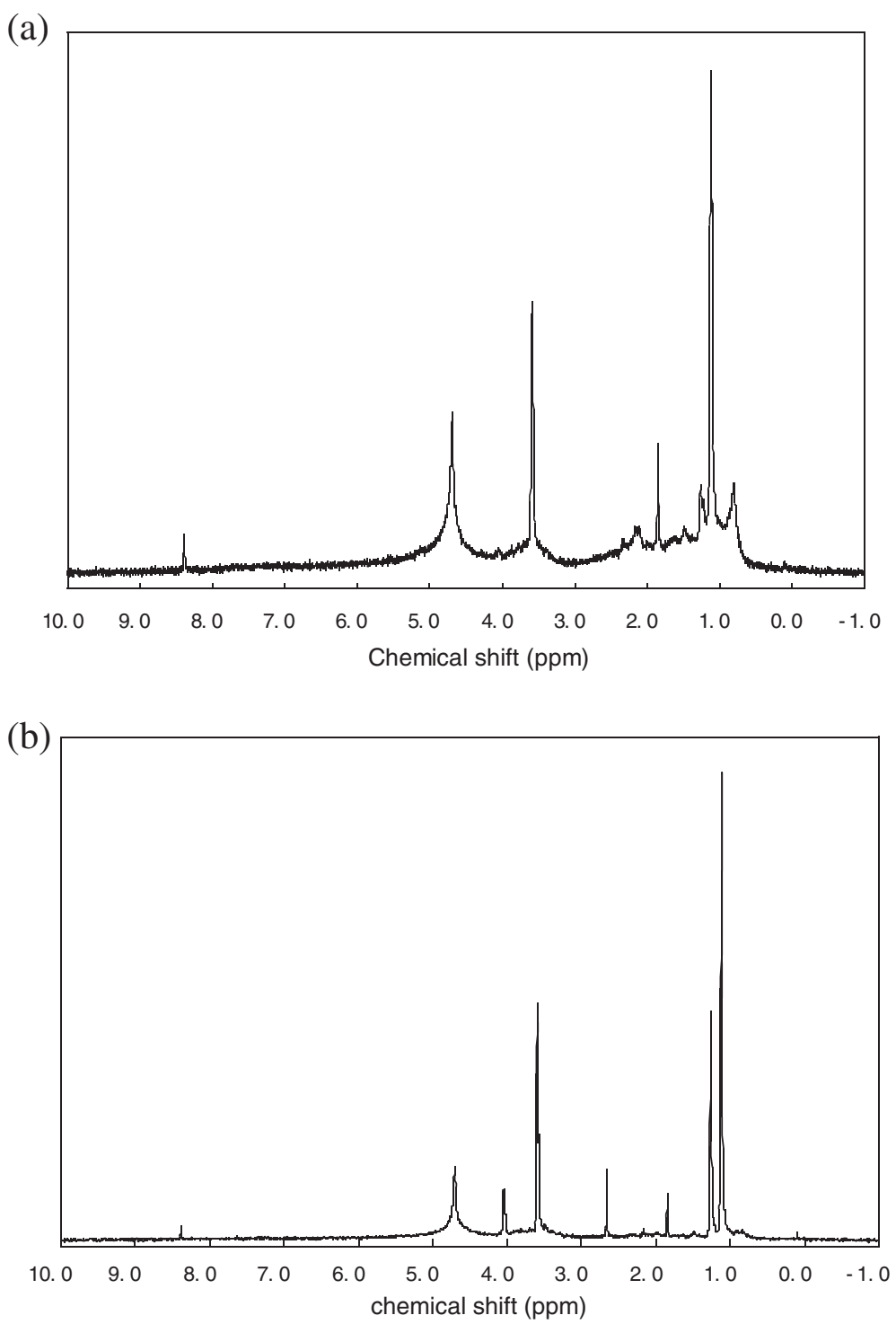

Figure $1{ }^{1} \mathrm{H}$ NMR spectra of DOM samples derived from (a) under plant soil, (b) ditch soil. 


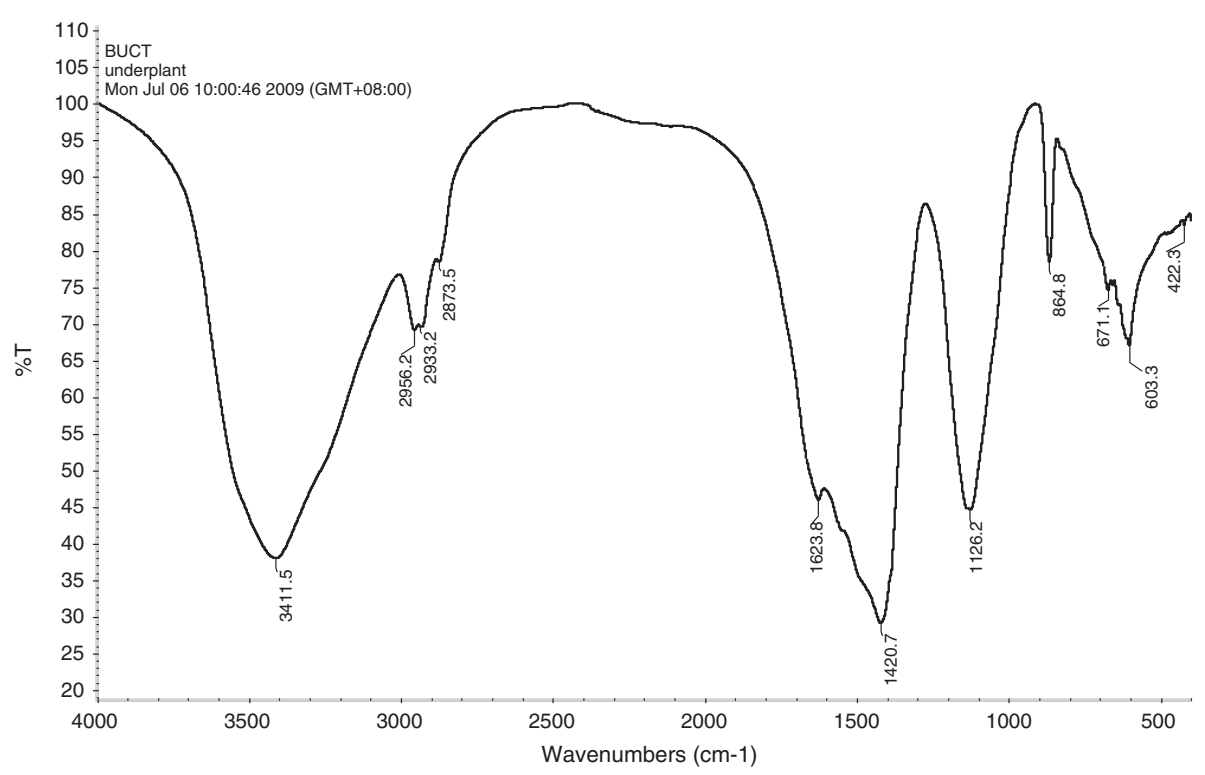

Figure 2 FTIR spectra of DOM samples derived from under plant soil.

The band at 2870 to $2970 \mathrm{~cm}^{-1}$ presented aliphatic carbons, of which two small peaks at 2964 and $2930 \mathrm{~cm}^{-1}$ were assigned to asymmetrical stretching of $\mathrm{C}-\mathrm{H}$ in methyl and methylene groups, respectively. Besides, a small peak at $2873 \mathrm{~cm}^{-1}$ was assigned to symmetrical stretching of $\mathrm{C}-\mathrm{H}$ in methyl groups; a strong absorbance at $1420 \mathrm{~cm}^{-1}$ exhibited paraffinic characteristics.

\section{Effect of soil properties on the sorption of PAHs}

Sorption isotherms of PHE and PYR by two soils are presented in Table 2 and Figure 3 and the data were fitted well with Freundlich sorption model. The isotherm trends for both soils were similar, which are concave-up. Whereas the binding affinity of PAHs to ditch soil was lower than that to under plant soil. The sorption coefficient $\left(K_{d}\right)$ value of PHE for under plant soil can be expressed as $K_{d}=1.425 \times 389 \times C_{e}^{0.425}$, and the values varied from 285 to $542 \mathrm{~L} / \mathrm{kg}$ with the initial system PHE concentration varying from 50 to $400 \mathrm{mgkg}-1 ; K_{d}$ value of ditch soil can be expressed as $K_{d}=1.517 \times$ $302 \times C_{e}^{0.517}$, and the values varied from 231 to $490 \mathrm{~L} / \mathrm{kg}$, which was smaller than that of under plant soil. Similar results can be obtained for sorption of PYR.

The lower binding of PAHs to ditch soil may be attributed to two opposite effects. On the one hand, the relatively higher mineral content, especially the higher content of smectite and kaolinite would provide more internal surface sites, thus enhanced sorption (Sheng et al. 2001). Besides, the soil texture could also affect the sorption of PAHs. The relatively fine particle size of ditch soil may tend to sequence more PAHs. On the other hand, the SOM of ditch soil was only half of under plant soil, which would cause less the sorption of PAHs. Many previous studies have reported that the PAHs sorption was proportional to SOM content in soil-water system, that is, the higher SOM in system, the higher PAHs sorption (Gregory et al. 2005; Iorio et al. 2008; Cao et al. 2008). For the competition of these two contradicting effects, the SOM was predominant factor that determine the sorption and availability of PAHs in soil-water system (Chen et al. 2009b; Pignatello and Xing 1996).

Table 2 Isotherm parameters for the sorption of PHE and PYR from under plant and ditch soil by Freundlich simulation

\begin{tabular}{|c|c|c|c|c|c|c|}
\hline \multirow[t]{2}{*}{ Soil treatment } & \multicolumn{3}{|c|}{ Under plant } & \multicolumn{3}{|c|}{ Ditch } \\
\hline & $\log K_{f}$ & $N$ & $R^{2}$ & $\log K_{f}$ & $N$ & $R^{2}$ \\
\hline \multicolumn{7}{|l|}{ PHE } \\
\hline DOM removed & $2.712 \pm 0.074$ & $1.407 \pm 0.169$ & 0.959 & $2.534 \pm 0.049$ & $1.430 \pm 0.145$ & 0.969 \\
\hline Bulk & $2.590 \pm 0.051$ & $1.425 \pm 0.142$ & 0.971 & $2.480 \pm 0.039$ & $1.516 \pm 0.130$ & 0.978 \\
\hline \multicolumn{7}{|l|}{ PYR } \\
\hline DOM removed & $3.899 \pm 0.408$ & $1.370 \pm 0.219$ & 0.855 & $3.856 \pm 0.258$ & $1.403 \pm 0.216$ & 0.933 \\
\hline Bulk & $3.798 \pm 0.1595$ & $1.384 \pm 0.136$ & 0.963 & $3.811 \pm 0.121$ & $1.486 \pm 0.110$ & 0.981 \\
\hline
\end{tabular}


(a)

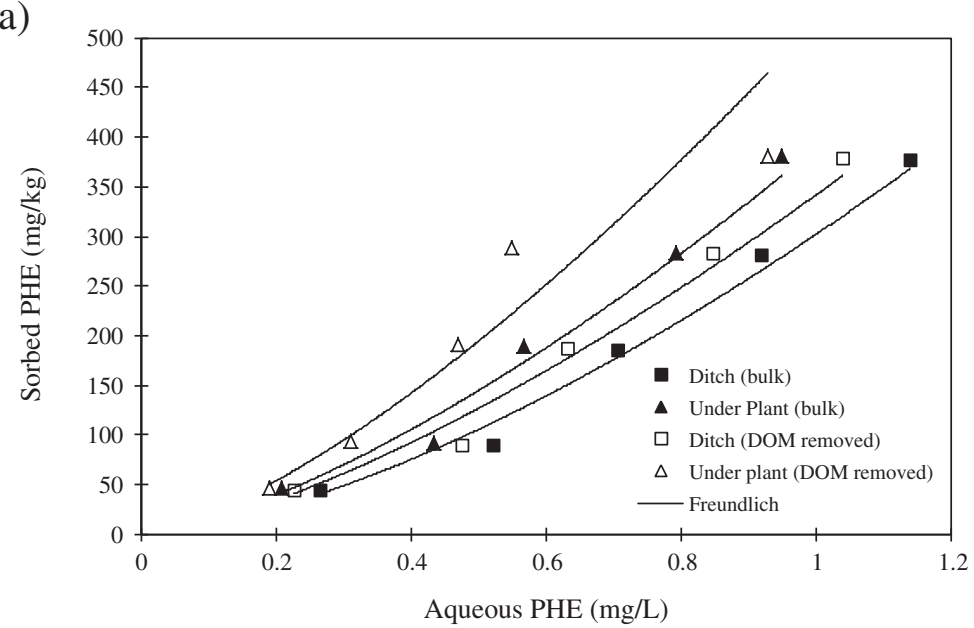

(b)

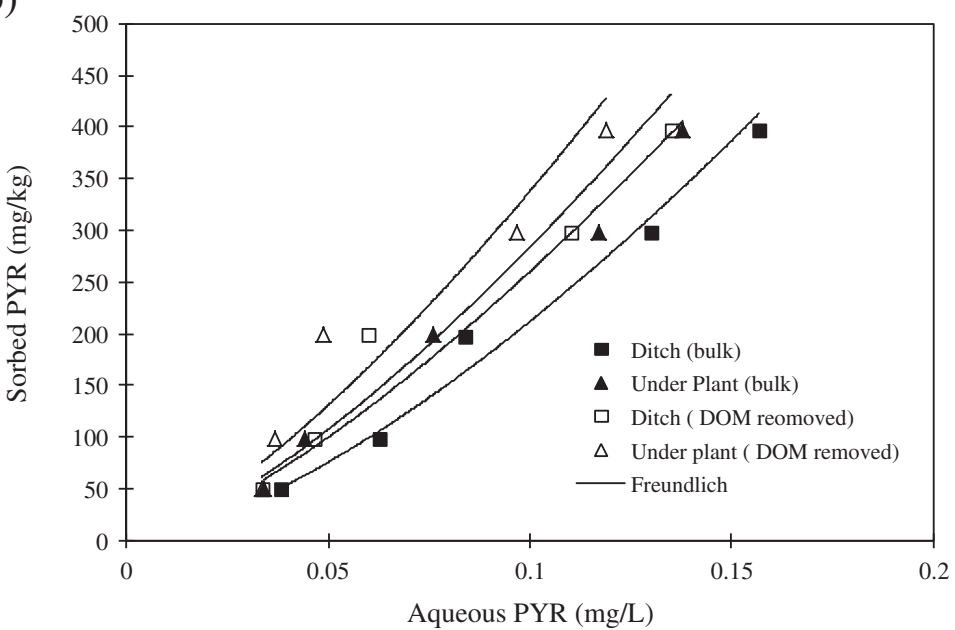

Figure 3 Sorption isotherms of (a) PHE and (b) PYR on ditch soil (bulk and DOM removed) and under plant soil (bulk and DOM removed).

The sorption isotherms of PHE and PYR to DOM removed and bulk soil in two soil samples were also compared and the results indicated that DOM had a strong effect on PAHs sorption (Figure 3). For both under plant and ditch soil, the sorption of soil treated with DOM removed was also higher than that of bulk soil. This is because the DOM in the aqueous phase will bind with PAHs, thus enhancing the PAHs concentration in aqueous phase. Also the sorption increase caused by DOM remove in under plant soil was slightly higher than ditch soil. In comparison of nuclear magnetic resonance (NMR) spectra of DOMs extracted from two soil samples, these two kinds of DOM exhibited similar compositions. While the DOM concentration in ditch soil was much lower than that in under plant soil. In addition, when comparing these two kinds of soils after removing of DOM, the sorption capacity of ditch soil was still much lower than that of under plant soil since the absolutely higher SOM content of under plant soil.
Effects of soil properties and biosurfactant on desorption of PAHs

The combined effects of DOM and biosurfactant on desorption isotherm of PHE and PYR for two kinds of soils were compared (Figure 4). For all combined systems, $50 \mathrm{ppm}$ of DOM and $200 \mathrm{ppm}$ of biosurfactant were added. In order to better compare the effect of DOM on desorption behavior of PAHs, under plant DOM were applied for two soils samples. All desorption isotherm data were fitted well with linear equation model, which meant that the partition was the predominant behavior (Yu et al. 2011). With the involvement of either biosurfactant or DOM, desorption extent for both PHE and PYR in the two soils were enhanced when compared with bulk soil systems. For PHE, the soil-water desorption partition coefficient $\left(K_{d}\right)$ in $200 \mathrm{ppm}$ biosurfactant addition system, $50 \mathrm{ppm}$ DOM added system and bulk system in under plant soil were 463,611 and $710 \mathrm{~L} / \mathrm{kg}$, respectively; the $K_{d}$ values in above three systems in ditch soil were 183, 286 
(a)

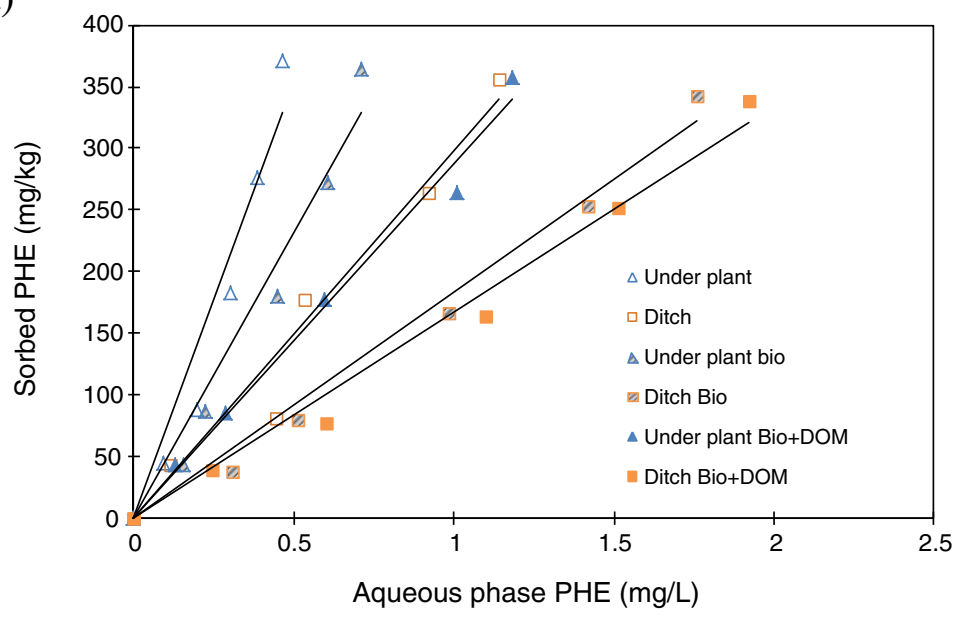

(b)

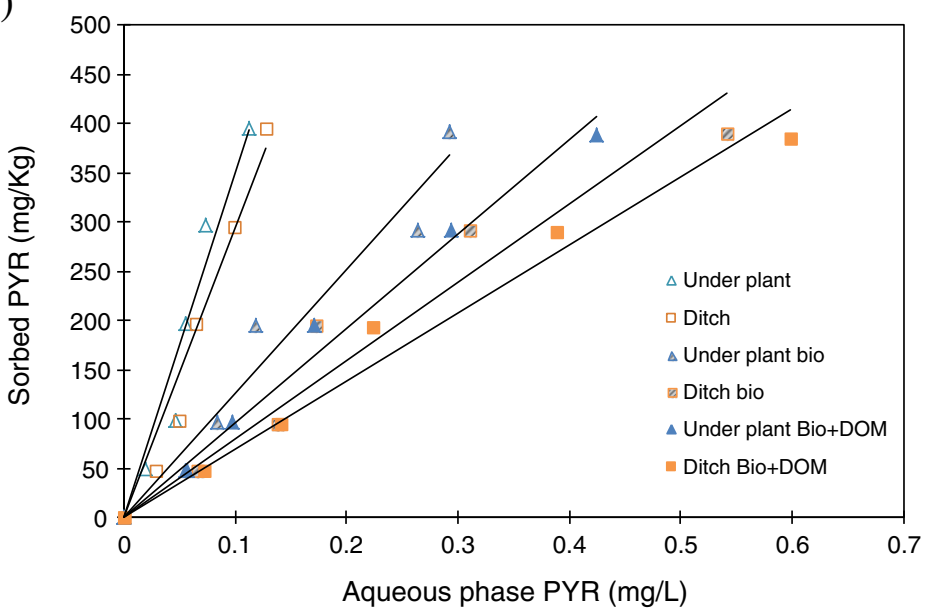

Figure 4 Combined effect of DOM and biosurfactant on the desorption of (a) PHE and (b) PYR.

and $297 \mathrm{~L} / \mathrm{kg}$, respectively. For desorption of PYR, similar results can be obtained. In addition, the desorption extent of PAHs were positively correlated with the concentrations of both DOM and biosurfactant. As discussed previous, desorption enhancement by DOM was due to the binding of PAH with DOM, which would enhance the aqueous PAHs content. Besides, biosurfactant could also enhance desorption of PAHs through increasing their solubility at concentrations greater than the CMC. According to our experimental design, biosurfactant concentrations in aqueous phase were above its CMC. With that, the desorption content of PAHs would increase with the surfactant aqueous micellar concentration.

In systems with combined DOM and biosurfactant, the desorption extent were significantly enhanced when compared with single DOM or biosurfactant system (Figures 4 and 5). That may attribute to the synergetic effects of DOM and biosurfactant in the soil water system. It can be also found that under the combined DOM and biosurfactant condition, more PAHs were desorbed from ditch soil. The $K_{d}$ value of PHE in ditch soil system and under plant soil system were 170 and $287 \mathrm{~L} / \mathrm{kg}$, which means that with the same concentration of PHE in solid phase, about $60 \%$ more of PHE were desorbed from ditch soil than under plant soil. Similar tendency can be found for PYR. Under the combined conditions, the $K_{d}$ value of PYE in ditch soil system and under plant soil system were 690 and $960 \mathrm{~L} / \mathrm{kg}$, respectively. With the same concentration of PYR in solid phase, about $40 \%$ more of PYR would be desorbed from ditch soil. The desorption difference in these two soil further indicated that the soil properties would significantly influence the contaminants detached from soil during the process of surfactant remediation.

When compared with the two site soils, in systems with the same concentrations of biosurfactant and DOM, the desorption extents of ditch soil were all significantly higher than those in under plant soil, with relatively lower soil-water phase partition coefficient. That's means the binding capacity of ditch soil was weaker than under plant 


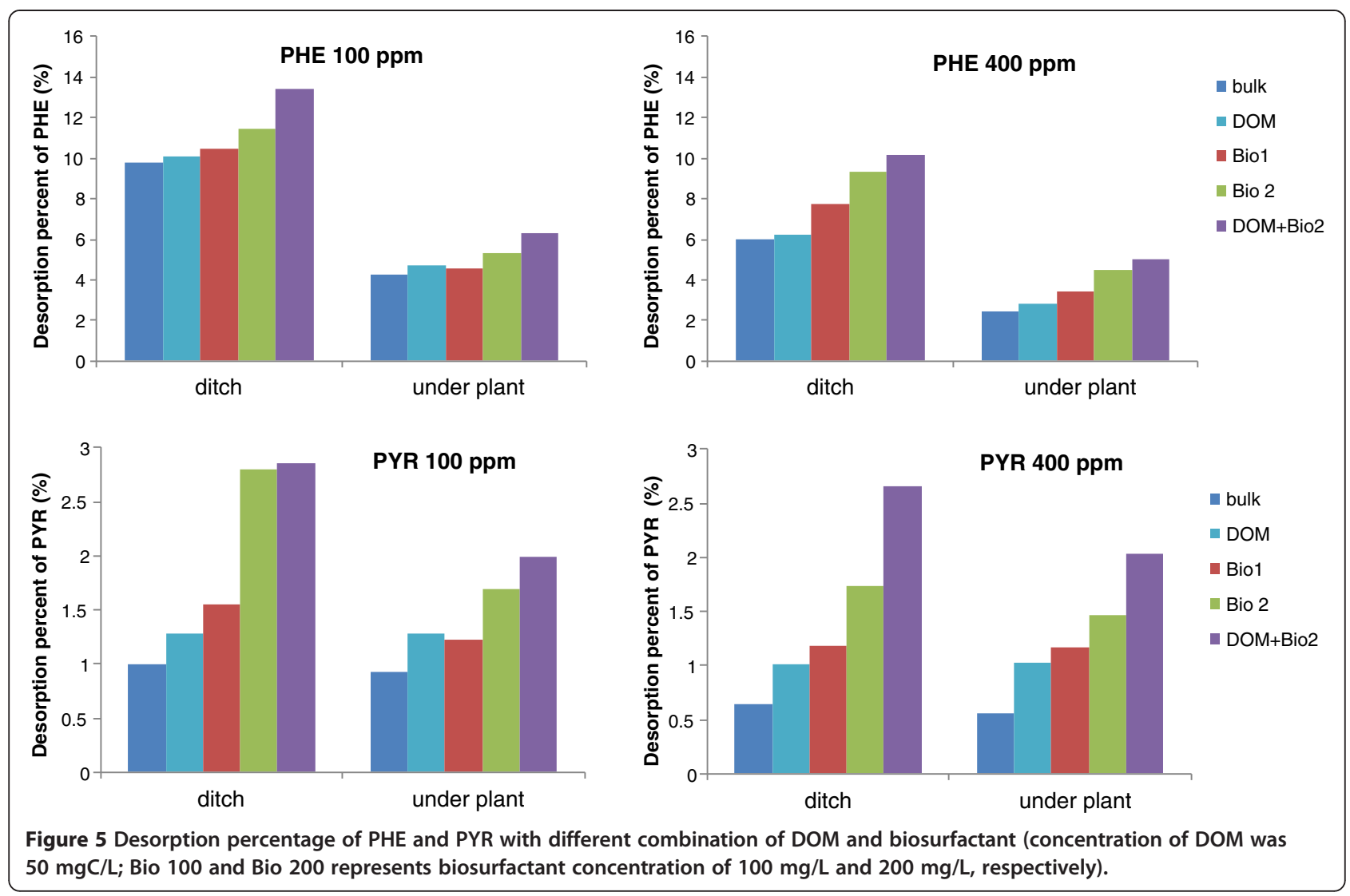

soil. The soil organic matter was still the key factor that determined the behaviors of PAHs in soil water systems.

In order to explore the interactive mechanisms of DOM and biosurfatcant with consideration of soil properties on desorption enhancement of PAHs, the mass desorption percent of PAHs in each systems were calculated (Figure 5). Generally, desorption extent in ditch soil were higher than under plant soil. And the desorption enhancement of PHE was much higher than that of PYR.

For desorption of PHE at low initial system concentration $(100 \mathrm{ppm})$, the desorption enhancement in $50 \mathrm{mgC} / \mathrm{L}$ DOM addition system, 200 ppm biosurfactant addition system and the combined DOM and biosurfactant system were $0.32 \%, 1.65 \%$ and $3.66 \%$, respectively when compared with the desorption in bulk system in ditch soil; the desorption enhancement in under plant soil in above three systems were $0.44 \%, 1.00 \%$ and $2.07 \%$, respectively. The desorption enhancement in the combined system was larger than the sum of enhancement in two single system for both soils, which showed synergistic effects. That can be explained as follows. Both surfactant and DOM are amphiphilic compounds, when they co-existence in the system, they may interact with each other through hydrophobic surface interaction or hydrogen bonding and form mixed micelles, resulting in synergistic effects. Similar results can be observed in previous studies (Yu et al. 2011; Wan et al. 2011; Cheng and Wong 2006). When the initial PHE concentration increase to $400 \mathrm{ppm}$, the desorption enhancement in combined system was still larger than the sum of individual system, however, the desorption extent in high concentration of PAHs system was lower than that in low concentration system in system with the same DOM/ and biosurfactant concentration. This can be explained as the competitions among PAHs, DOM and surfactant for sorption sites. In high solute concentration system, the competition for sorption site was more severely than low concentration system, with the similar aqueous concentration of DOM and biosurfactant (according to our preliminary experiment, there was no significant difference in sorption of biosurfactant and DOM in two system), Thus more PAHs were sequenced into soil phase in high $\mathrm{PAH}$ concentration system.

PAH desorption in 100 ppm and 200 ppm biosurfactant systems were also compared. When compared with bulk system, the desorption enhancement in $200 \mathrm{ppm}$ biosurfactant system was significantly higher than that in 100 ppm biosurfactant system, however, the enhancement percentage was not in proportional with the biosurfactant concentration, which was less than double in $100 \mathrm{ppm}$ biosurfactant system. This is due to the 
competitions among aqueous surfactant, sorbed surfactant and solute. In 100 ppm biosurfactant system, the percentage of biosurfactant sorbed by soil was higher than that in $200 \mathrm{ppm}$ biosurfactant system for systems with the same sorption sites. The sorbed surfactant may also bind some of PAHs, resulting in the less PAHs desorbed from soil. Besides, the desorption of PYR showed similar tendency with that of PHE, however significantly lower desorption percentage. Competition existed between PHE and PYR for sorption site. PYR had relatively higher hydrophobic property and show preference in the competition.

\section{Conclusions}

The interactive mechanisms of soil properties, biosurfactant and pollutants in soil water system were investigated in this study and following main conclusions can be obtained: (1) SOM was predominant soil component affecting PAHs sorption/desorption and degradation; it also influenced the biosurfactant partition in soil and aqueous phase. (2) The presence of DOM in soil-water system could increase PAHs desorption from soil, however, the strong binding of DOM and PAHs would decrease their bioavailability. (3) Desorption of PAHs in the combined DOM and biosurfactant system would be significantly enhanced when compared with those in single system. The study results should be helpful in broadening knowledge of biosurfactant enhanced bioremediation of PAHs in contaminated soil.

\section{Methods \\ Materials}

Phenanthrene (PHE) and pyrene (PYR) were purchased from Sigma Aldrich Chemical Co. (Oakville, ON) with a purity $>98 \%$. The biosurfactant used in this study is rhamnolipid, which is the most commonly isolated biosurfactant. A rhamnolipid solution was purchased from the Jeneil Biosurfactant Company (Saukville, Wis, USA). Specifically, Jeneil product JBR425 with a mono- to di-rhamnolipid ratio of $1: 1$ was used. The biosurfactant was supplied as a $10 \%$ aqueous solution.

\section{Soil preparation and characterization}

Two kinds of soil samples, under plant soil and ditch soil, respectively, were obtained from Coleville site in Saskatchewan, Canada. The under plant soil was collected at a depth of 3 to 5 feet right below the plant ground surface. The ditch soil was obtained from north garden of Coleville at a depth of 3 to 5 feet.

The soil samples were air dried at room temperature $\left(25 \pm 2^{\circ} \mathrm{C}\right.$ ) for one week. Soils were ground and passed through a $1.0 \mathrm{~mm}$ stainless steel sieve in order to improve the homogeneity of the soil. The physicochemical properties of the soils are given in Table 1.
To investigate the effect of soil organic matter on the sorption and desorption of PHE and PYR, soil samples with dissolved organic matter (DOM) were used as a comparison of bulk soil. The removal of soil DOM was gone through the following procedures. The soils were extracted with $1 \mathrm{mM} \mathrm{CaCl}_{2}$ (soil: solution, 1:20 (w/v)) for $6 \mathrm{~h}$ and at least 3 consecutive times and then centrifuged at $7200 \mathrm{~g}$ for $30 \mathrm{~min}$. The residues were collected and freeze dried.

The physicochemical properties of soils were characterized in order to understand their impact on sorption, desorption and subsequent biodegradation experiments. The analytical methods listed below were applied.

(1) $\mathrm{pH}$

Soil $\mathrm{pH}$ is a measure of the activity of ionized $\mathrm{H}\left(\mathrm{H}^{+}\right)$in the soil solution (Margesin and Schinner 2005). A total of $5 \mathrm{~g}$ air dried soil and $10 \mathrm{ml}$ of $0.01 \mathrm{M}$ $\mathrm{CaCl}_{2}$ were mixed together. The mixture was shaken for 2 hour at $100 \mathrm{rpm}$ and let stand for 10 minutes. The $\mathrm{pH}$ was then measured using a benchtop $\mathrm{pH} /$ temperature meter (410A Plus; Thermo Orion, Waltham, MA, USA).

\section{(2) Cation exchange capacity}

The cation exchange capacity (CEC) was determined using the sodium acetate-sodium chloride saturation and magnesium nitrate extraction method (Pansu and Gautheyrou 2006). The two step procedure is as follows: 1), saturation of cation exchange sites with $\mathrm{Na}^{+}$ by "equilibration" of the soil with a $0.4 \mathrm{~N} \mathrm{NaOAc}-0.1 \mathrm{~N}$ $\mathrm{NaCl}$ solution; 2), total $\mathrm{Na}$ and $\mathrm{Cl}$ were extracted with $0.5 \mathrm{~N} \mathrm{MgS04}$ solution so that the soluble $\mathrm{Na}$ from the excess saturating solution could be deducted from the total Na. This provides the exchangeable $\mathrm{Na}$, which is equivalent to the CEC.

\section{(3) SOM content}

The total organic matter is routinely estimated by measuring organic carbon content. The method is described as a wet-oxidation procedure using potassium dichromate $\left(\mathrm{K}_{2} \mathrm{Cr}_{2} \mathrm{O}_{7}\right)$ with external heat and back-titration to measure the amount of unreacted dichromate (Jones 2001). The detailed procedures have been described by Mebius (1960).

\section{(4) Soil classification}

Soil classification was performed in accordance with the standard of International Soil Science Society. The International Classification system was applied to categorize the soil.

(5) Clay analysis

The soil clay mineral was determined by X-ray diffraction (XRD) (Whittig and Allardice 1982). The 
procedure was described by Hwang (Hwang 2001). The clay with particle size finer than $2 \mu \mathrm{m}$ (according to the International Soil Science Society method) was applied, which was collected by elutriation. The samples were previously subjected to disintegration and dispersion processes through ultrasound. Organic residues were eliminated with a $10 \% \mathrm{H}_{2} \mathrm{O}_{2}$ solution. This was done to obtain the largest amount of clay needed for the different treatments. Once the fraction smaller than 2 microns was separated, washed with demineralized water and placed on flat glass to dry. The methodology consisted of three initial pretreatments in order to identify and differentiate the principal clay group present in the sample: 1) The water suspended clay was allowed to dry in order to permit the free arrangement of the basal planes of the clays; 2) Saturated with Ethylene glycol, organic molecules occupied the interiaminar portion of the smectites in order to enlarge the basal distance. This identified the smectite group; 3) Heating of the samples to $550^{\circ} \mathrm{C}$ destroyed the crystal structure of the kaolinites. This identified kaolinites, chlorites and some of the interstratified groups.

\section{Characterization of dissolved organic matter}

For the DOM collection, twenty grams of clean soil sample was placed in $200 \mathrm{ml}$ deionized water and agitated on a reciprocal shaker at $200 \mathrm{rpm}$ and $20 \pm 1^{\circ} \mathrm{C}$ for 24 hours. The supernatants were collected after centrifugation at $12000 \mathrm{~g}$ for $20 \mathrm{~min}$ and then filtered through a $0.45 \mu \mathrm{m}$ sterilized membrane (PALL Corporation, Michigan, USA). The extracts could be stored at $4^{\circ} \mathrm{C}$ in the dark with maximum of 5 days. The filtrates were freeze-dried for further analysis.

The concentration of DOM was measured using TOC5000A Analyzer (Shimadzu, Kyoto Japan). TOC concentration of each soil measured was the dissolved organic carbon (DOC) concentration since TOC in soil matrix was dissolved into the aqueous phase. DOM concentration was hypothesized to equal to or a fractional equivalent of the DOC concentration in this study. The ratio of absorbance of DOM at 465 and $665 \mathrm{~nm}$ (E4/E6) was measured to evaluate changes in the molecular weight of the DOM fractions, which is negatively correlated with molecular size (Marschner et al. 2005; Yang et al. 2007; Korshin et al. 1997).Specific UV absorbance at $254 \mathrm{~nm}$ was determined to estimate the aromaticity of DOM samples (Yang et al. 2007). The absorbance of water samples was measured at the selected wavelength on a $2100 \mathrm{spec}-$ trophotometer (Unic, Shanghai, China). Deionized water was used as reference. Functional groups of DOM were determined through ${ }^{1} \mathrm{H}$ liquid-state NMR spectroscopy analysis on a Bruker Avance 600 MHR spectrometer
(Billerica, MA) and Fourier transform infrared (FTIR) spectral analysis using aThermo Electron Nexus 8700 Spectrophotometer (Waltham, MA).

\section{Batch sorption and desorption experiment}

For both sorption and desorption isotherm experiments, triplicate tests were conducted using the standard batch equilibration method. All experiments were carried out in $25 \mathrm{~mL}$ Corex centrifuge tubes with Teflon-lined screw caps (Fisher Scientific, Ottawa, ON, Canada). For the sorption experiment, an appropriate volume of PHE and PYR dichloromethane stock solution was respectively added to each tube. Dichloromethane was allowed to evaporate, and then $0.5 \mathrm{~g}$ soil and $10 \mathrm{~mL}$ background solution were added to each vial. The background solution contained $0.01 \mathrm{M} \mathrm{CaCl}_{2}, 0.01 \mathrm{M} \mathrm{NaCl}$, and $0.01 \mathrm{M}$ $\mathrm{NaN}_{3}$. The $\mathrm{CaCl}_{2}$ and $\mathrm{NaCl}$ were used as electrolyte to poise the ionic strength, and the $\mathrm{NaN}_{3}$ was used as inhibitor for bacterial growth. This approach resulted in initial soil concentrations of 50,100, 200, 300 and 400 ppm for PHE and PYR, respectively.

The centrifuge tubes were vortexed for $20 \mathrm{~s}$, and then placed on a reciprocal shaker at $20 \pm 1^{\circ} \mathrm{C}$ and $125 \mathrm{rpm}$ for 24 hours to reach the sorption equilibrium. The suspensions were then centrifuged at $5000 \mathrm{~g}$ for $25 \mathrm{~min}$ under the same temperature. PHE and PYR in the aqueous phase were extracted with dichloromethane, and their concentrations were analyzed through GC. The amount of PAHs sorbed to the soil was obtained through calculating the difference between the initial amount and remaining in the solution.

Desorption isotherm experiments were conducted immediately after the sorption experiments. The supernatants in sorption tubes were completely removed. To study the effects of DOM and biosurfactant on PAHs desorption, $10 \mathrm{~mL}$ fresh background solution containing different concentrations of DOM and biosurfactant was successively added into the tube, and then shaked for another 24 hours to reach desorption equilibrium. The subsequent separation of soil and aqueous phase as well as the relevant analyses were conducted as described in the sorption experiments. The sorption of PHE and PYR on the wall of centrifuge tubes was considered negligible; the amounts of PAHs blank before and after mixing (without soil) did not show significant difference between each other.

\section{Analytical methods}

The concentrations of PHE and PYR were analyzed through Gas Chromatography (Varian GC 3800-FID) system coupled with a Varian 8200 autosampler. The GC was equipped with a $25 \mathrm{~m} \times 0.32 \mathrm{~mm}$ ID DB-5 column with $0.25 \mu \mathrm{m}$ film thickness (J\&W Scientific Inc., CA). Helium is used as the carrier gas with flow rate of 
$1.5 \mathrm{ml} / \mathrm{min}$. The oven temperature was held at $40^{\circ} \mathrm{C}$ for $1.5 \mathrm{~min}$ then ramped to $175^{\circ} \mathrm{C}$ at a rate of $50^{\circ} \mathrm{C} / \mathrm{min}$. The temperature was held at $175^{\circ} \mathrm{C}$ for $1 \mathrm{~min}$, then ramped to $220^{\circ} \mathrm{C}$ at $7^{\circ} \mathrm{C} / \mathrm{min}$, and held at this final temperature for $1 \mathrm{~min}$. The injector temperature was $250^{\circ} \mathrm{C}$, and the detector temperature was $230^{\circ} \mathrm{C}$. Injection was made in the split mode with a ratio of 50 (since $1.75 \mathrm{~min}$ ).

The sorption and desorption isotherms of PAHs were mathematically fitted with a Freundlich sorption and linear distribution models.

The Freundlich model has the following form:

$$
C_{s}=K_{f} C_{e}^{n}
$$

The linear model has the following form:

$$
C_{s}=K_{p} C_{e}
$$

where $C_{s}$ is the sorbed PAH concentration $(\mathrm{mg} / \mathrm{kg})$; $C_{e}$ is the solution-phase PAH concentration $(\mathrm{mg} / \mathrm{L})$; $K_{p}(\mathrm{mg} / \mathrm{kg})(\mathrm{mg} / \mathrm{L})$ is the distribution coefficient; $K_{f}$ $(\mathrm{mg} / \mathrm{kg})(\mathrm{mg} / \mathrm{L})^{-\mathrm{n}}$ is the sorption constant at a given temperature; $K_{f}$ represents the sorption capacity evaluated at $\mathrm{C}_{\mathrm{e}}=1 \mathrm{mg} / \mathrm{L} \mathrm{n}$ is the isotherm exponent. Equation (6.1) can be linearized by a logarithmic transformation:

$$
\log c_{s}=\log k_{f}+n \log c_{e}
$$

Freundlich parameters for sorption $\left(\mathrm{K}_{\mathrm{fA}}\right.$, and $\left.\mathrm{n}_{\mathrm{A}}\right)$ and desorption $\left(\mathrm{K}_{\mathrm{fD}}, \mathrm{n}_{\mathrm{D}}\right)$ were respectively calculated through fitting Equation (6.3) to the observed data.

The sorption coefficient $K_{d}$ can be defined as:

$$
K_{d}=d C_{s} / d C_{e}=n K_{f} C^{n-1}
$$

For parallel experiment, means and standard deviations are calculated for pooled results using Microsoft ${ }^{\circ}$ Excel. To analyze the results from sorption and desorption experiments, F-tests are conducted using Minitab statistical software (Minitab Inc., State College, PA, USA). The introduced level of significance is $5 \%(\alpha=0.05)$. One-way analysis of variance (F-test with $\mathrm{p}<0.05)$ is performed to determine significant differences between different treatments.

\footnotetext{
Abbreviations

SOM: Soil organic matter; DOM: Dissolved organic matter; PAHs: Polycyclic aromatic hydrocarbons; HOCs: Hydrophobic organic contaminants; CMC: Critical micellar concentration; PHE: Phenanthrene; PYR: Pyrene; CEC: Cation exchange capacity; FTIR: Fourier transform infrared.
}

\section{Competing interests}

The authors declare that they have no competing interests.

\section{Authors' contributions}

HY conducted most of the experiment and drafted the manuscript. $\mathrm{HX}$ participated in the design of the experiments and helped to draft the manuscript. DW participated the soil characteristics analysis and helped to draft the manuscript. All authors read and approved the final manuscript.

\section{Acknowledgements}

This research was supported by National Nation Science Foundation (51109078 and 51102093) and Natural Science and Engineering Research Council of Canada.

\section{Author details}

${ }^{1}$ Department of Chemical Engineering, University of New Brunswick, Fredericton, NB, E3B 5A3, Canada. ${ }^{2} \mathrm{MOE}$ Key Laboratory of Regional Energy Systems Optimization, S\&C Academy of Energy and Environmental Research, North China Electric Power University, Beijing 102206, China. ${ }^{3}$ Ministry of

Agriculture, Government of Saskatchewan, Regina, SK, S4S OB1, Canada.

Received: 12 December 2013 Accepted: 8 January 2014

Published: 17 January 2014

\section{References}

Abu-Zreig M, Rudra RP, Dickinson WT (2003) Effect of application of surfactants on hydraulic properties of soils. Biosyst Eng 84(3):363-372

Akkanen J, Tuikka A, Kukkonen JVK (2005) Comparative sorption and desorption of benzo [a] pyrene and 3, 4,3',4 '-tetrachlorobiphenyl in natural lake water containing dissolved organic matter. Environ Sci Technol 39(19):7529-7534

Brady NC, Weil RR (2000) Elements of the nature and properties of soils. Prentice-Hall, Upper Saddle River, New Jersey

Cao J, Guo H, Zhu HM, Jiang L, Yang H (2008) Effects of SOM, surfactant and pH on the sorption-desorption and mobility of prometryne in soils. Chemosphere 70(11):2127-2134

Chen JL, Wong YS, Tam NFY (2009a) Static and dynamic sorption of phenanthrene in mangrove sediment slurry. J Hazard Mater 168(2-3):1422-1429

Chen W, Hou L, Luo XL, Zhu LY (2009b) Effects of chemical oxidation on sorption and desorption of PAHs in typical Chinese soils. Environ Pollut 157(6):1894-1903

Cheng KY, Wong JWC (2006) Combined effect of nonionic surfactant Tween 80 and DOM on the behaviors of PAHs in soil-water system. Chemosphere 62(11):1907-1916

Cheng KY, Zhao ZY, Wong JWC (2004) Solubilization and desorption of PAHs in soil-aqueous system by biosurfactants produced from Pseudomonas aeruginosa P-CG3 under thermophilic condition. Environ Technol 25(10):1159-1165

Gregory ST, Shea D, Guthrie-Nichols E (2005) Impact of vegetation on sedimentary organic matter composition and polycyclic aromatic hydrocarbon attenuation. Environ Sci Technol 39(14):5285-5292

Hwang S (2001) Effect of soil properties, compound aging, and presence of cosolute on sorption, desorption, and biodegradation of polycyclic aromatic hydrocarbons in natural soils. PhD dissertation. University of Akron, Akron, Ohio, pp 65-66

Hwang S, Cutright TJ (2003) Statistical implications of pyrene and phenanthrene sorptive phenomena: effects of sorbent and solute properties. Arch Environ Con Tox 44(2):152-159

Hwang S, Ramirez N, Cutright TJ, Ju LK (2003) The role of soil properties in pyrene sorption and desorption. Water Air Soil Poll 143(1-4):65-80

lorio M, Pan B, Capasso R, Xing BS (2008) Sorption of phenanthrene by dissolved organic matter and its complex with aluminum oxide nanoparticles. Environ Pollut 156(3):1021-1029

Jones JB (2001) Laboratory guide for conducting soil tests and plant analysis. Boca Raton, FL

Korshin GV, Li CW, Benjamin MM (1997) Monitoring the properties of natural organic matter through UV spectroscopy: a consistent theory. Water Res 31(7):1787-1795

Kuyukina MS, Ivshina IB, Makarov SO, Litvinenko LV, Cunningham CJ, Philp JC (2005) Effect of biosurfactants on crude oil desorption and mobilization in a soil system. Environ Int 31(2):155-161

Lee JF, Hsu MH, Lee CK, Chao HP, Chen BH (2005) Effects of soil properties on surfactant adsorption. J Chin Inst Eng 28(2):375-379

Lu L, Zhu LZ (2012) Effect of soil components on the surfactant-enhanced soil sorption of PAHs. J Soil Sediment 12(2):161-168

Makkar RS, Rockne KJ (2003) Comparison of synthetic surfactants and biosurfactants in enhancing biodegradation of polycyclic aromatic hydrocarbons. Environ Toxicol Chem 22(10):2280-2292

Margesin R, Schinner F (2005) Manual for soil analysis: monitoring and assessing soil bioremediation. Determination of chemical and physical soil properties, Springer Berlin Heidelberg 

Sci 56(3):299-306

Mebius $L J(1960)$ A rapid method for the determination of organic carbon in soil. Anal Chim Acta 22(2):120-124

Pan B, Ghosh S, Xing B (2007) Nonideal binding between dissolved humic acids and polyaromatic hydrocarbons. Environ Sci Technol 41(18):6472-6478

Pansu M, Gautheyrou J (2006) Handbook of soil analysis: mineralogical, organic and inorganic methods. cation exchange capacity. Springer, Berlin Heidelberg

Pignatello JJ, Xing BS (1996) Mechanisms of slow sorption of organic chemicals to natural particles. Environ Sci Technol 30(1):1-11

Raber B, Kogel-Knabner I, Stein C, Klem D (1998) Partitioning of polycyclic aromatic hydrocarbons to dissolved organic matter from different soils. Chemosphere 36(1):79-97

Rodriguez-Escales P, Borras E, Sarra M, Folch A (2013) Granulometry and surfactants, key factors in desorption and biodegradation (T. Versicolor) of PAHs in soil and groundwater. Water Air Soil Pollut 224(2):1422-1433

Sheng GY, Johnston CT, Teppen BJ, Boyd SA (2001) Potential contributions of smectite clays and organic matter to pesticide retention in soils. J Agr Food Chem 49(6):2899-2907

Shin KH, Kim KW, Ahn Y (2006) Use of biosurfactant to remediate phenanthrenecontaminated soil by the combined solubilization-biodegradation process. $J$ Hazard Mater 137(3):1831-1837

Wan JZ, Wang LL, Lu XH, Lin YS, Zhang ST (2011) Partitioning of hexachlorobenzene in a kaolin/humic acid/surfactant/water system: Combined effect of surfactant and soil organic matter. J Hazard Mater 196:79-85

Wen B, Zhang JJ, Zhang SZ, Shan XQ, Khan SU, Xing BS (2007) Phenanthrene sorption to soil humic acid and different humin fractions. Environ Sci Technol 41(9):3165-3171

Whittig LD, Allardice WR (1982) X-ray diffraction techniques: in methods of soil anaysis: part 1 - physical and mineralogical methods. Americal Society of Agronomy and Soil Science of America, Madison, WI

Wilcke W (2000) Polycyclic aromatic hydrocarbons (PAHs) in soil - a review. J Plant Nutr Soil Sc 163(3):229-248

Woods CE Jr (2004) Examination of the effects of biosurfactant concentration on natural gas hydrate formation in seafloor porous media. M.S., Mississippi State University, United States - Mississippi

Yang WC, Hunter W, Spurlock F, Gan J (2007) Bioavailability of permethrin and cyfluthrin in surface waters with low levels of dissolved organic matter. J Environ Qual 36(6):1678-1685

Yu HS, Zhu LZ, Zhou WJ (2007) Enhanced desorption and biodegradation of phenanthrene in soil-water systems with the presence of anionic-nonionic mixed surfactants. J Hazard Mater 142(1-2):354-361

Yu H, Huang GH, An CJ, Wei J (2011) Combined effects of DOM extracted from site soil/compost and biosurfactant on the sorption and desorption of PAHs in a soil-water system. J Hazard Mater 190(1-3):883-890

Zhu HB, Aitken MD (2010) Surfactant-enhanced desorption and biodegradation of polycyclic aromatic hydrocarbons in contaminated soil. Environ Sci Technol 44(19):7260-7265

doi:10.1186/2193-2697-3-6

Cite this article as: Yu et al:: Effects of soil properties and biosurfactant on the behavior of PAHs in soil-water systems. Environmental Systems Research 2014 3:6.

\section{Submit your manuscript to a SpringerOpen ${ }^{\circ}$ journal and benefit from:}

- Convenient online submission

- Rigorous peer review

- Immediate publication on acceptance

- Open access: articles freely available online

- High visibility within the field

- Retaining the copyright to your article

Submit your next manuscript at $\gg$ springeropen.com 